\title{
Polypharmacy and cost analysis in patients suffering from type 2 diabetes mellitus with associated comorbidities
}

\author{
Snehal R. Dhongdi ${ }^{1 *}$, Riyaz A. Siddiqui ${ }^{2}$ \\ ${ }^{2}$ Department of Pharmacology, ${ }^{1,2} \mathrm{NKP}$ Salve Institute of Medical Sciences and Research Centre, Nagpur, Maharashtra, \\ India
}

Received: 14 March 2020

Revised: 15 April 2020

Accepted: 16 April 2020

*Correspondence:

Dr. Snehal R. Dhongdi,

Email: dhongdisnehal97@gmail.com

Copyright: $\odot$ the author(s), publisher and licensee Medip Academy. This is an open-access article distributed under the terms of the Creative Commons Attribution Non-Commercial License, which permits unrestricted non-commercial use, distribution, and reproduction in any medium, provided the original work is properly cited.

\section{ABSTRACT}

Background: Diabetes mellitus is a common health problem worldwide, associated with several co-morbidities. It requires longer therapy, and is crippling in terms of cost management. The objective of this study was to evaluate comorbidities in patients suffering from type 2 diabetes and concomitant medications used along with antidiabetic drugs, also analyzing individually cost of drug therapy.

Methods: It is an observational, cross sectional study. The study was conducted at outpatient department, Medicine at a tertiary care hospital. Prescriptions of patients attending the clinic, suffering from type 2 diabetes were analyzed for antidiabetic drugs and other concomitant medications for associated co-morbidities. Their age, sex, number of medications and their costs were noted.

Results: Out of 60 patients evaluated, 36 (60\%) were males and 24 (40\%) were females. Hypertension in $54(90 \%)$ of the patients and hyperlipidaemia in $23(38.33 \%)$ are the important comorbidities. Metformin was most commonly prescribed antidiabetic drug in this study in $41(68 \%)$, followed by glimepiride $18(30 \%)$, tenegliptin $10(16.67 \%)$, voglibose in $6(10 \%)$ and others. Mean cost of drug therapy to a person was INR 1408.8 per month and INR 16905.6 per annum.

Conclusions: Hypertension 54 (90\%) and hyperlipidaemia 23 (38.33\%) were the most common associated comorbidities. Metformin and glimepiride were the most common antidiabetic drugs used. Antihypertensive and hypolipidemics were commonly prescribed concomitant medications. Mean cost of drug therapy per person was INR 1408.8 per month and INR 16905.6 per annum.

Keywords: Comorbidities, Diabetes mellitus, Indian national rupee

\section{INTRODUCTION}

Diabetes is a group of chronic metabolic diseases characterized by hyperglycaemia resulting from defects in insulin secretion, insulin action, or both. The majority of cases fall into either: Type 1- $\beta$-cell destruction, usually leading to absolute insulin deficiency or type 2 - insulin resistance with relative insulin deficiency to predominantly an insulin secretory defect with insulin resistance. ${ }^{1}$ The prevalence of diabetes is predicted to double globally from 171 million in 2000 to 366 million in 2030 with a maximum increase in India. It is predicted that by 2030 diabetes mellitus (DM) may afflict up to 79.4 million individuals in India, while China (42.3 million) and the United States (30.3 million). ${ }^{2}$

DM is associated with various co morbid conditions such as hypertension, hyperlipidaemia, and cardiovascular 
disorders. Hypertension or elevated blood arterial pressure affects about $70 \%$ of diabetic patients and the risk of development of hypertension is twice for diabetic patients compared to euglycemic individuals. ${ }^{3}$ Dyslipidaemia is often associated with diabetes and is found to increase risk of cardiovascular disorders. A study in 2013 in Gujarat, India, showed $15.41 \%$ were prescribed hypolipidemic drug atorvastatin, inclusion of antiplatelet therapy in diabetic patient is essential to reduce the chances of ischemia. $^{4}$

Diabetics with co morbidities are facing more economic burden per year wise when compared with subjects having only diabetes. In a study which included 132 subjects, $60 \%$ of patients are hospitalized with comorbidities and facing economic burden for hospitalization, travelling and other costs like cost of diagnosis. Many of the patients are facing economic burden, even sometimes they are not able to consume sufficient quantity of medications due to the high costs. ${ }^{5}$ Since there are few studies carried out in this field, authors have undertaken this study to find out actual level of polypharmacy associated with type II DM, related co morbidities and the cost of drug therapy associated with it.

Since very few studies are conducted in this field, present study aims at evaluating co-morbidities in patients suffering from type 2 diabetes, other concomitant medications along with antidiabetic medications in patients suffering from type $2 \mathrm{DM}$, and to analyze cost per day of drug therapy to the individual.

\section{METHODS}

It is an observational, cross sectional study. Study conducted at Outpatient Department of Medicine, NKP Salve Institute of Medical Sciences and Research Centre, Digdoh hills, Hingna, Nagpur, Maharashtra. The duration of the study was from October 2019 to March 2020.

Anticipated percentage of at least one morbidity is $83 \%$ as per reference. ${ }^{6}$ Sample size formulation is done by

$\mathrm{n}=\frac{4 p q}{L^{2}}, \alpha=5 \%, \beta=20 \%$.

So, the required sample size $=56$

\section{Inclusion criteria}

Patients suffering from type 2 DM, attending the outpatient department of medicine, both males and females, patients with signed informed consent form, patients receiving at least one antidiabetic drug and other concomitant medications prescribed by physician in clinic at NKPSIMS were included.

\section{Exclusion criteria}

Lactating or pregnant women, nursing a child and paediatric age groups, unwilling patients, critically ill patients (e.g., cancer patients, diabetic foot), bedridden patients were excluded.

The study was conducted at the outpatient department of Medicine after the permission of ethical committee. Presciptions of patients attended the clinic suffering from type 2 diabetes was analysed for the antidiabetic drugs and other concomitant drugs received for associated co morbid conditions. Their age, sex, number of drugs the patient has received and their costs were also noted.

Ethics committee Approval was taken prior to the study.

\section{Statistical analysis}

Data collected and analyzed for proportion.

\section{RESULTS}

During the study period, authors have analyzed prescriptions of 60 patients suffering from type 2 diabetes, receiving antidiabetic drugs and other concomitant medications for other comorbidities. The study population age ranges from 31-90 years of age. $36(60 \%)$ were males and $24(40 \%)$ were females. Out of these $39(65 \%)$ patients belonged to the age group of 51-70 years, followed by 25 $(15 \%)$ in the age group of 71-90 years and $6(10 \%)$ patients belong to 31-50 years age group, as shown in Table 1 .

Table 1: Distribution of patients in various age groups.

\begin{tabular}{|lll|}
\hline Age (in years) & No. of patients & Percentage \\
\hline $\mathbf{3 1 - 5 0}$ & 6 & 10.00 \\
\hline $\mathbf{5 1 - 7 0}$ & 39 & 65.00 \\
\hline $\mathbf{7 1 - 9 0}$ & 15 & 25.00 \\
\hline Total & 60 & 100.00 \\
\hline
\end{tabular}

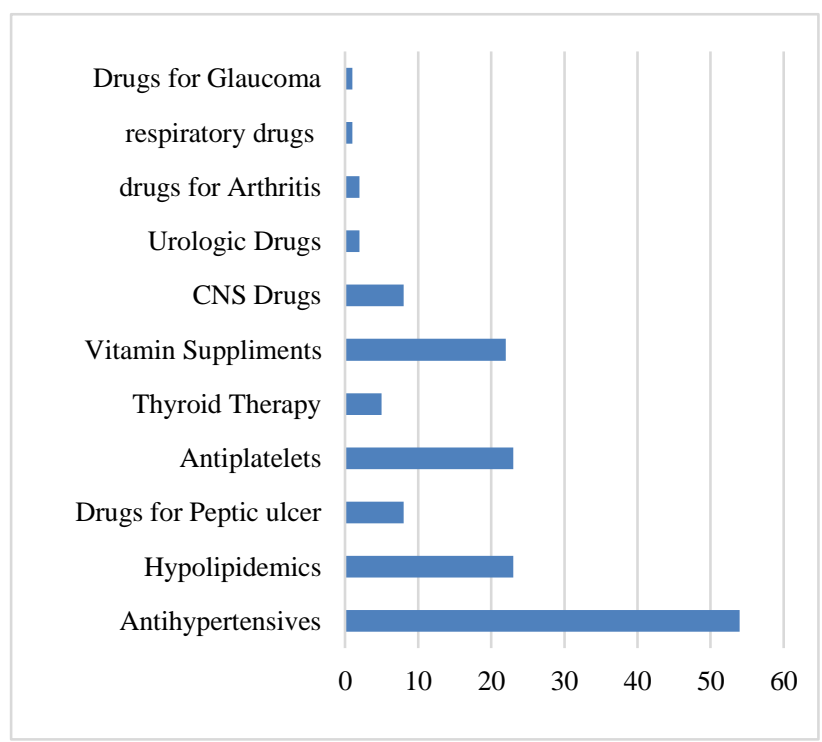

Figure 1: Concomitant medications prescribed in diabetic patients for comorbidities. 
Table 2: Patients suffering from other comorbid conditions.

\begin{tabular}{|llllll|}
\hline \multirow{2}{*}{ Comorbid condition } & Age group (in years) & & Total & Percentage \\
\hline Hypertension & $\mathbf{3 1 - 5 0}$ & $\mathbf{5 1 - 7 0}$ & $\mathbf{7 1 - 9 0}$ & & 90.00 \\
\hline Hyperlipidemia & 3 & 38 & 13 & 54 & 38.33 \\
\hline Cardio vascular diseases & 1 & 15 & 7 & 23 & 38.33 \\
\hline Neurological & 2 & 11 & 10 & 23 & 13.33 \\
\hline GI disorders (acidity, GERD) & 0 & 3 & 5 & 8 & 13.33 \\
\hline Endocrine disorders & 0 & 5 & 3 & 8 & 8.33 \\
\hline Musculoskeletal & 4 & 1 & 0 & 5 & 3.33 \\
\hline Nephrological disorders & 0 & 2 & 0 & 2 & 3.33 \\
\hline Respiratory disorders & 0 & 1 & 1 & 2 & 1.67 \\
\hline Eye disorders & 0 & 0 & 1 & 1 & 1.67 \\
\hline
\end{tabular}

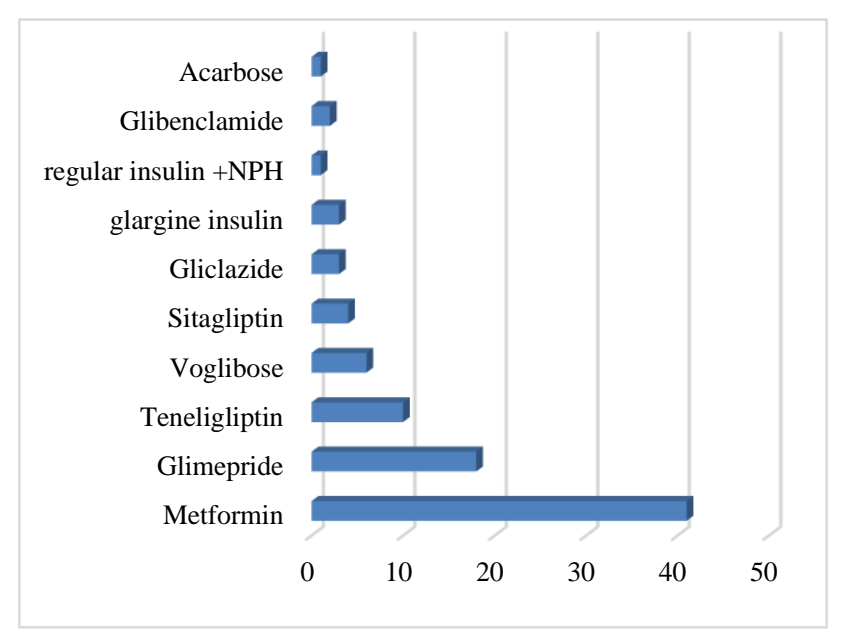

Figure 2: Anti diabetic drugs.

DM patients suffer from various comorbidities. The present study revealed $54(90 \%)$ of the patients suffered from hypertension, $23(38.33 \%)$ suffered from hyperlipidemia and other cardiovascular conditions, 8 $(13.3 \%)$ with gastrointestinal and neurological disorders followed by others as shown in Table 2. The different classes of concomitant medications prescribed included antihypertensives in $54(90 \%)$, hypolipidemics in 23 (38\%), antiplatelet therapy in $23(38 \%)$, vitamin supplements in $22(37 \%)$, drugs for peptic ulcer in 8 $(13 \%)$, nervous system drugs in $8(13 \%)$, thyroid therapy in $5(8 \%)$ followed by others as shown in bar graph, Figure 1.

The antidiabetic drugs most commonly prescribed in this study to the type 2 diabetic patients included metformin in $41(68 \%)$, followed by glimepiride $18(30 \%)$, tenegliptin $10(16.67 \%)$, voglibose $6(10 \%)$, sitagliptin in $4(6.67 \%)$ followed by others as shown in Figure 2. Apart from antidiabetic, various other classes of medications were co prescribed.

The cost of diabetes therapy increases linearly along the duration of diabetes. The cost of all the drugs, including other comorbid conditions, were calculated on per day basis. Mean cost of drug therapy per person came out to be INR (Indian national rupee) 1408.8 per month and 16905.6 per year respectively from Table 3 .

Table 3: Mean cost of drug therapy per person.

\begin{tabular}{|lll|}
\hline $\begin{array}{l}\text { Age } \\
\text { group } \\
\text { (in year) }\end{array}$ & Total cost & Mean cost $($ Rs) \\
\hline $\mathbf{3 1 - 5 0}$ & 135 & 22.5 \\
\hline $\mathbf{5 1 - 7 0}$ & 1991 & 51.05 \\
\hline $\mathbf{7 1 - 9 0}$ & 1010 & 67.33 \\
\hline \multicolumn{2}{|l|}{ Average cost per day $=\mathbf{4 6 . 9 6}$} \\
\hline
\end{tabular}

\section{DISCUSSION}

DM is a disease of improper metabolism of carbohydrate, proteins, and fat. Diabetes is associated with various other disorders such as hypertension, hyperlipedemia, nephrological, and neurological problems. Thus, very often, they are being prescribed with more than 1 drug. Polypharmacy or the use of multiple medicines for a single patient not only increases the pill burden for the patient but also aggravates the chance of drug-drug and drug-food interactions. ${ }^{6}$ Cost of the drug therapy also increases with these comorbidities. The present study was designed to evaluate the comorbidities in patients suffering from type 2 diabetes and other concomitant medications along with antidiabetic medications and to analyze cost of drug therapy to the individual. Out of 60 patients, $36(60 \%)$ were males and $24(40 \%)$ were females. A study conducted in Gujarat, India observed that patient suffering from diabetes were $50.4 \%$ males and $49.6 \%$ females. ${ }^{4}$ A study in Nepal also depicted that $59.59 \%$ were males and $43.41 \%$ were females. $^{7}$ These findings were in accordance to this study in which prevalence of diabetes among males as compared to the females.

There are various comorbid conditions associated with diabetes. In this study $54(90 \%)$ of the patients suffered from hypertension, $23(38.33 \%)$ from hyperlipedemia and other cardiovascular conditions, 8 (13.3\%) with 
gastrointestinal and neurological disorders. In a drug utilizing study in Bengal most of the patients (74\%) were suffering from comorbid conditions like hypertension ( $50.8 \%$ patients), dyslipidemia ( $24.3 \%$ patients), etc. The comorbidities played a major role on the disease burden and also it increases cost of therapy and deteriorates the quality of life. In a study at Vijayawada, Hypertension (HTN) (39.8\%, male; $39.7 \%$, female) is the most predominant co-morbidity, followed by patients with both HTN and cardio vascular diseases (9.4\%, male; 9.8\%, female) ${ }^{8}$ In a prospective cross-sectional study at UAE most common comorbidities associated with type 2 diabetes was found to be Hypertension $(83.40 \%)$ followed by obesity $(90.49 \%)$ and dyslipidemia $(93.43 \%) .{ }^{9}$ In a study conducted at Bankura Medical College $74.0 \%$ were suffering from associated comorbidities. Hypertension $(50.8 \%)$ being the commonest comorbidity followed by dyslipidemia $(24.3 \%)$, neuropathy $(13.8 \%)$ coronary vascular diseases $(10.5 \%)$ and nephropathy $(3.9 \%)$. These findings are in accordance with this study in which hyper tension is the most common comorbidity. ${ }^{10}$ Both hyperlipidemia and hypertension increase the propensity of cardiovascular disorders among diabetic patients. Researches showed that around $80 \%$ of the diabetic patients die because of cardiovascular disorders. ${ }^{11}$

Metformin was the most commonly prescribed antidiabetic drug in this study in $41(68 \%)$, followed by glimepiride $18(30 \%)$, tenegliptin 10 (16.67\%), voglibose in $6(10 \%)$, sitagliptin in $4(6.67 \%)$ etc. In a study at Bengal, Metformin was the most commonly prescribed drug $(79.6 \%)$, followed by sulfonylurea class of drugs $(66.9 \%) .{ }^{12}$ A study at a Sikkim teaching hospital also found Metformin to be the most commonly prescribed drug $(79.6 \%)$, followed by sulfonylurea class of drugs $(66.9 \%)$. Glimiperide was the most commonly used sulfonylurea. Glimepiride and metformin were the most common combinations used $(45.5 \%){ }^{13}$ In a teaching hospital in Uttar Pradesh, out of 282 Patients it was observed that $183(64.89 \%)$ patients were prescribed metformin, $152(53.90 \%)$ patients sulfonylureas group of drugs of which glimepride $(24.11 \%)$ was the most commonly prescribed. ${ }^{14}$ These findings are in accordance with this study. Concomitant medications prescribed in this study are antihypertensives in 54 (90\%), hypolipidemics in $23(38 \%)$, antiplatelet therapy in 23 $(38 \%)$ followed by others. These findings are also seen in other studies. . $^{6}$

The burden of DM is increasing in India and across states. Given the chronic and progressive nature of the disease, it implicates huge financial burden on patients. The cost of diabetes therapy increases linearly along the duration of diabetes. In this study mean cost of drug therapy per person was INR 1408.8 per month and INR 16905.6 per annum. In study conducted among 206 patients at a tertiary care hospital in Odisha, the average total expenditure per patient per month was INR 1265 (95\% confidence interval 1178-1351), of which medical expenditure was INR 993 (95 confidence interval 912-1075) and that of nonmedical expenditure was INR Rs. 271 (95 confidence interval 251292). ${ }^{15}$ In a study conducted in at a south Indian hospital, a total of 116 each diabetic with or without complications found that, diabetic patient without complications spend Rs.917.73 compared to the diabetic patients with complications who spends on an average of Rs.1448.51 per month leading to the annual cost of Rs.22,456.97 and Rs.30,634.45/- respectively. ${ }^{16}$ Mean cost of therapy for a month for a diabetic patient was $354.60 \pm 305.72$ INR in a Gujarat study. ${ }^{4}$ In a study the lifetime cost for all drugs was estimated using mean was found to be approximately Indian National Rupee Rs.1,945,135, for antidiabetic drugs alone, lifetime cost using the mean comes out to be Rs.1,518,540 approximately.

\section{CONCLUSION}

Hypertension 54 (90\%) and hyperlipedemia 23 (38.33\%) were the most common associated comorbidities. Metformin continues to be the choice of oral hypoglycemic agent $41(68 \%)$, followed by glimepiride 18 (30\%), tenegliptin $10(16.67 \%)$ and others. Antihypertensives and hypolipidemics were the commonly prescribed concomitant medications. Since the disease is chronic and associated with various comorbidities the use of antidiabetic drugs along with various other drugs implicates huge financial burden on patients. The cost of diabetes therapy increases linearly along the duration of diabetes. In this study, mean cost of all the drugs including for other comorbid conditions was Rs. 1408.8 per month and Rs.16905.6 per annum respectively.

Funding: No funding sources

Conflict of interest: None declared

Ethical approval: The study was approved by the Institutional Ethics Committee

\section{REFERENCES}

1. American Diabetes Association. Diagnosis and classification of diabetes mellitus. Diabetes care. 2014;37(Suppl 1):S81-90.

2. Kaveeshwar SA, Cornwall J. The current state of diabetes mellitus in India. Austr Medi J. 2014;7(1):45-8.

3. Purohit P. A cross-sectional study of type-2 diabetic females at a higher CVD risk owing to a strong correlation of Systolic hypertension to CVD risk factors. Int J Biol Med Res. 2012;3(3):1905-9.

4. Acharya KG, Shah KN, Solanki ND, Rana DA. Evaluation of antidiabetic prescriptions, cost and adherence to treatment guidelines: A prospective, cross-sectional study at a tertiary care teaching hospital. J Basic Clini Pharm. 2013;4(4):82-7.

5. Swamy PN, Rao VR. Pharmacoepidemiological and economic evaluation of diabetes mellitus patients with comorbidities, Eur J Pharmaceut Medi Res. 2017;4(9):812-9.

6. Indu R, Adhikari A, Maisnam I, Basak P, Sur TK, Das AK. Polypharmacy and comorbidity status in the 
treatment of type 2 diabetic patients attending a tertiary care hospital: An observational and questionnaire-based study. Perspectiv Clini Res. 2018;9(3):139-44.

7. Upadhyay DK, Palaian S, Ravi Shankar P, Mishra P, Sah AK. Prescribing pattern in diabetic outpatients in a tertiary care teaching hospital in Nepal. J Clin Diagn

8. Nuthakki S, Pendyala S, Vallabhu C, Kilaru N, Challa SR, Pingili R. An Assessment of Anti-hyperglycemic Drug Utilization Patterns and Adherence to AACE/ACE 2015 Guidelines in South Indian Tertiary Care Teaching Hospital. Ind $\mathbf{J}$ Pharm Pract. 2016;9(4):225.

9. Jelinek HF, Osman WM, Khandoker AH, Khalaf K, Lee S, Almahmeed $\mathrm{W}$, et al. Clinical profiles, comorbidities and complications of type 2 diabetes mellitus in patients from United Arab Emirates. BMJ Open Diab Res Care. 2017;5(1):e000427.

10. Mandal S, Maiti T, Das AK, Das A, Mandal A, Sarkar BS, et al. Drug utilization study in patients with type 2 diabetes mellitus attending diabetes clinic of a tertiary care hospital in rural Bengal. Int $\mathbf{J}$ Basic Clin Pharmacol. 2016;5(4):1647-54.

11. Adhikari A, Indu R, Bhowal T, Sur TK, Das AK, Chakraborty P. Evaluation of adverse effects due to antidiabetic and cardiovascular drugs in a tertiary care hospital in Kolkata, West Bengal, India. Int J Pharmaceut Sci Res. 2016;7(7):3101.
12. Singla R, Bindra J, Singla A, Gupta Y, Kalra S. Drug prescription patterns and cost analysis of diabetes therapy in India: Audit of an endocrine practice. Ind $\mathbf{J}$ Endocrinol Metab. 2019;23(1):40-5.

13. Satpathy SV, Datta S, Upreti B. Utilization study of antidiabetic agents in a teaching hospital of Sikkim and adherence to current standard treatment guidelines. J Pharm Bioall Sci. 2016;8(3):223-8.

14. Pankaj CK, Satendra SP, Dhananjay P, Kumud R, Rajmangal C, Bhanu P. A prospective study on drug utilization pattern of anti-diabetic drugs in a tertiary care teaching hospital of eastern Uttar Pradesh, India. Int J Res Medi Sci. 2019;7(3):669-75.

15. Swain SP, Samal S, Sahu KS, Rout SK. Out-of-pocket expenditure and drug adherence of patients with diabetes in Odisha. J Family Medi Primary Care. 2018;7(6):1229-35.

16. Acharya LD, Rau NR, Udupa N, Rajan MS, Vijayanarayana K. Assessment of cost of illness for diabetic patients in South Indian tertiary care hospital. J Pharm Bioal Sci. 2016;8(4):314-20.

Cite this article as: Dhongdi SR, Siddiqui RA. Polypharmacy and cost analysis in patients suffering from type 2 diabetes mellitus with associated comorbidities. Int J Basic Clin Pharmacol 2020;9:929-33. 